\title{
Offering a choice between NIPT and invasive PND in prenatal genetic counseling: the impact of clinician characteristics on patients' test uptake
}

\author{
Sanne L. van der Steen ${ }^{1} \cdot$ Diewertje Houtman ${ }^{1} \cdot$ Iris M. Bakkeren ${ }^{1} \cdot$ Robert-Jan H. Galjaard ${ }^{1}$ Marike G. Polak ${ }^{2}$. \\ Jan J. Busschbach ${ }^{3} \cdot$ Aad Tibben $^{4} \cdot$ Sam R. Riedijk $^{1}$
}

Received: 29 March 2018 / Revised: 18 September 2018 / Accepted: 28 September 2018 / Published online: 8 October 2018

(c) European Society of Human Genetics 2018

\begin{abstract}
Testing options for pregnant women at increased risk of common aneuploidies are non-invasive prenatal testing (NIPT) and invasive prenatal diagnosis (PND). Clinicians are challenged to comprehensively discuss the complex information in a patient-centered and non-directive manner, to allow for patients' informed decision-making. This study explored the information-centeredness, patient-centeredness, and level of non-directivity of different clinicians and examined group differences between their patients. First, semi-structured interviews with four senior obstetricians and one senior nurse were held regarding their information provision, their adaptation of a patient-centered attitude, and their practice of nondirectivity. Interviews were transcribed verbatim and rated by four independent researchers. Secondly, 181 pregnant women were included in the study, of whom $82 \%$ opted for NIPT and $18 \%$ chose PND. Between clinicians, we assessed the distribution of choice ratios, patients' impression of clinicians' test preferences, and patients' knowledge scores. The results indicate that clinicians do not differ in their information-centeredness, but do differ in their patient-centeredness and their level of non-directivity. Significant differences in patients' NIPT/PND ratios were observed between clinicians, with the largest difference being 35 vs. $4 \%$ opting for invasive PND. Between 9 and $22 \%$ of the patients had an impression of their clinician's preference and chose in accordance with this preference. Patients' overall knowledge scores did not differ across clinicians. In conclusion, the differences in NIPT/PND ratios between clinicians indicate that clinicians' differing counseling approaches affect the choices their patients make. The interviews indicate a possible framing effect which may unintentionally steer the decision-making process.
\end{abstract}

These authors contributed equally: Sanne L. van der Steen, Diewertje Houtman

$\triangle$ Diewertje Houtman

d.houtman@erasmusmc.nl

1 Department of Clinical Genetics, Erasmus Medical Center, Rotterdam, The Netherlands

2 Department of Psychology, Education \& Child Studies (DPECS), Erasmus University Rotterdam, Rotterdam, The Netherlands

3 Department of Psychiatry, section Medical Psychology and Psychotherapy, Erasmus Medical Center, Rotterdam, The Netherlands

4 Department of Clinical Genetics, Leiden University Medical Center, Leiden, The Netherlands

\section{Introduction}

Because of recent developments in prenatal genetic testing, more testing options have become available for pregnant women. Women with an abnormal first trimester screening (FTS) result need to make important decisions about how they wish to proceed in their prenatal care. As of now, pregnant women in the Netherlands have three options: (1) no further testing, (2) invasive prenatal diagnosis (PND), and (3) non-invasive prenatal testing (NIPT), as depicted in Fig. 1.

The primary goal of pre-test counseling is to enable the pregnant woman and her partner to make an informed choice and to give informed consent for either NIPT or invasive PND, or refrain from further testing. The eventual decision should reflect the principles of informed choice and is based on relevant knowledge, consistent with the couple's values, and behaviorally implemented, i.e., the decision 


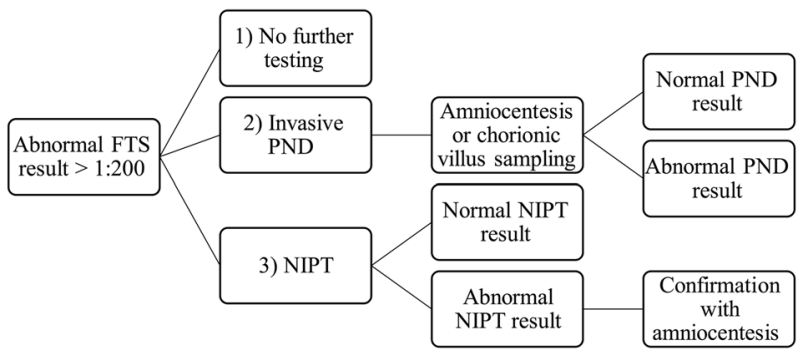

Fig. 1 Flowchart of prenatal testing options after abnormal first trimester screening (FTS) result

must be documented and when requested a test must be performed [1]. During pre-test counseling, information is provided about the benefits and limitations of both NIPT and invasive PND, as well as the potential to detect findings other than the indication for testing.

Besides informing pregnant women and their partners, the clinician should address individual attributes of the patient, such as emotions and resilience [2]. A focus on patient-centeredness in prenatal counseling is expected to lead to more well-deliberated choices and less psychological distress for patients [3, 4]. Kessler [5] has differentiated between the teaching model and the counseling model. Whereas the teaching model aims for educated patients, the counseling model aims for patients to feel understood, in control, and competent. These outcomes are desirable, but also require a much broader set of counseling skills. The clinician should then not only inform, but should also elicit information from patients about their needs and use this information to guide the counseling session $[5,6]$.

Genetic counseling traditionally implies a non-directive attitude. According to Kessler [7], non-directive counseling aims to facilitate patients to think about their options, which is different from directive counseling, aiming to prescribe and influence the patients' behavior. While directive counseling involves persuasive coercion, thereby targeting the decision outcome, non-directive counseling promotes the patient's autonomy and self-directedness, so that the decision-making process is optimized $[5,6]$.

A recent Dutch study demonstrated that nationwide, about 3\% of pregnant women with an increased FTS result chose invasive prenatal testing while about $97 \%$ chose NIPT [8]. At the Erasmus Medical Center in the Netherlands, nearly $20 \%$ of the pregnant women opted for invasive PND while around $80 \%$ chose NIPT [9]. The difference in choice ratio may be explained by this center's different policy regarding invasive prenatal testing. Whereas other academic centers in the Netherlands perform quantitative fluorescence-polymerase chain reaction (QF-PCR) on fetal DNA to examine chromosomes 13,18 and 21 , here, high resolution SNP array at $0.5 \mathrm{Mb}$ is performed to analyze all chromosomes at a submicroscopic level [10]. This microarray provides much more detailed information on additional chromosomal aberrations.

The increasing scope of possible findings provided by SNP array and NIPT may jeopardize sound prenatal genetic counseling [11]. As the complexity of genetic counseling increases, it may become demanding for pregnant women and their partners to understand the test characteristics and implications [12-14]. Subsequently, the informed decisionmaking process of pregnant women and their partners requires more extensive pre-test counseling.

The higher invasive PND uptake rate at the Erasmus Medical Center compared to other academic centers, and the even more challenging task of clinicians to comprehensively discuss the different testing options and test outcomes of PND with their patients, increases the need to explore the approach of the different clinicians in this center and the content of their prenatal genetic counseling. Therefore, we explored the information-centeredness, patient-centeredness, and level of non-directivity of different clinicians by means of semi-structured interviews. We used data analysis to compare the ratio of patients' choices for either NIPT or invasive PND between clinicians and we examined whether patients had an impression of their clinicians' preferences. Finally, we assessed whether there were group differences in patients' knowledge scores between clinicians.

\section{Subjects and methods}

In this study, qualitative and quantitative data were collected. Qualitative data about clinician characteristics were obtained by semi-structured interviews. Quantitative data about group differences between patients of different clinicians were obtained from previously collected data [9].

\section{Qualitative data}

Clinicians working at the Erasmus University Medical Center in Rotterdam who provided counseling to more than 15 patients in an earlier study [9] were eligible for the qualitative interview study $(N=5)$. All five clinicians had senior positions, with $15+$ years of experience in the prenatal genetic testing field. One clinician was a senior nurse, the other four clinicians were senior gynecologists/obstetricians. The senior obstetricians performed chorionic villus sampling and amniocentesis themselves, whereas the senior nurse did not. The age range of clinicians was $42-51$ years. Two clinicians were men and three were women. All clinicians were familiar with providing counseling for invasive PND, and when NIPT was introduced in the Netherlands, they were formally trained in a Dutch national program about offering this choice alongside invasive PND as part of 
the Trial by Dutch laboratories for Evaluation of Noninvasive Prenatal Testing (TRIDENT). A 30 min counseling was provided to pregnant women who had an increased risk based on FTS and who subsequently had to choose between no further testing, NIPT, and invasive prenatal testing. In total, 185 pregnant women were randomly assigned to the clinicians in this study. Four women refrained from further testing and since we were interested in test choice, these women were excluded for further analyses. The number of patients counseled by clinicians 1 to 5 were respectively 49 , $71,23,15$, and 23. Clinicians participated in semistructured interviews held by two researchers (SS and $\mathrm{DH})$. The clinicians and some of the researchers (SS; SR) knew each other and had worked together before. These professional relationships formed a basis of mutual trust, which ensured that the clinicians were willing to participate and discussed their profession in an open and honest way. The interviews focused on three important themes of prenatal genetic counseling, as previously described in the introduction: (1) information-centeredness, (2) patient-centeredness, and (3) non-directivity.

First, the clinicians were asked how and to what extent they inform pregnant women and their partners about the choice between NIPT and invasive PND (information-centeredness), i.e., the different choice options, goals and methods of testing, test characteristics and limitations, riskcommunication, turnaround time of results, and possible outcomes and implications. Veach et al. [2] stated that 'presentation and discussion of relevant information allows patients to gain improved understanding and develop a new or different perspective'. Second, it was explored how and to what extent the clinician addresses the pregnant women's and their partners' thoughts, feelings, values, family dynamics, and psychosocial context and promotes emotional well-being by giving support, validation, and assistance with coping; patient-centeredness [2]. The balance between patient-centeredness and information centeredness was discussed. Third, it was explored to what degree clinicians adopted the concept of non-directivity in their counseling. In the exploration of this concept, directiveness and nondirectiveness were not used as categorical opposites, but rather as extremes on a continuum related to the level of patient autonomy [15]. Clinicians elaborated on the existence and definition of non-directivity and on how this concept was implemented in their counseling. We asked clinicians whether at times they were inclined to provide directive advice about the best option for the patient and whether clinicians had a personal preference towards a specific test.

To illustrate clinician characteristics scores, we have selected several quotes from each clinician regarding his/her level of information-centeredness, patient-centeredness, and non-directivity. Although these quotes are fragments of the answers clinicians gave during the interviews, we consider them to be typical of the clinician's approach.

\section{Qualitative analysis}

The interviews were conducted in Dutch and transcribed verbatim. Transcripts were anonymized for researchers SR and AT. The transcriptions of the interviews were scored by four independent researchers (SS; DH; SR; AT). Using a five-point Likert scale, the researchers each formed an individual evaluation of the clinicians' level of informationcenteredness $(1=$ very low to $5=$ very high), patientcenteredness $(1=$ very low to $5=$ very high $)$, and the degree of non-directivity $(1=$ fully directive, i.e., low patient autonomy to $5=$ fully non-directive, i.e., high patient autonomy). Four researchers rated the five clinicians on three categories, resulting in 15 ratings per researcher. More than two points difference between researchers' ratings was regarded as substantial, and a consensus meeting was held to discuss these differences. Subsequently, researchers could adjust their individual scores, eliminating these substantial differences. After adjustment of the scores, for each clinician, the mean score on each of the three concepts was calculated. Finally, for all 15 sets of four ratings we calculated both the percentage absolute agreement between researchers and the percentage of ratings with not more than one point difference (on the five-point scale) between researchers.

\section{Quantitative data}

Pregnant women and their partners who visited the outpatient clinic of prenatal medicine in the Erasmus Medical Center, University Medical Center Rotterdam, between April 2014 and November 2015 were invited to participate in a study [9] measuring informed choice in patients opting between NIPT and invasive PND. When the pregnant women agreed to participate, an informed consent form was signed. The local Medical Ethical Committee (METC) exempted this study (number: MEC-2013-314). For the present paper, we made use of the same data, however, we compared patients scores between clinicians instead of between test choice.

Inclusion criteria for the patients were: (a) an elevated risk on common aneuploidies based on first-trimester screening and (b) engaging in either NIPT or invasive PND. Exclusion criteria were: (1) a recurrence risk for trisomies based on earlier pregnancies or heredity, (2) a fetal nuchal translucency $>3.5 \mathrm{~mm}$, (3) ultrasound abnormalities, and (4) patients who were counseled in satellite hospitals in the South-West region of the Netherlands. One hundred and eighty-one pregnant women were included in the study. 
Consenting participants completed a questionnaire after counseling that assessed: (1) their choice for either NIPT or PND, (2) their impression of the clinician's preference, and (3) their level of knowledge. The Dutch version of the StateTrait Anxiety Inventory (STAI) [16] was used to assess anxiety symptoms. FTS results were reported. Social demographic background, level of education, nationality, age, religiosity, and obstetric history were collected. The ratios of patient's choices for either NIPT or invasive PND between clinicians were computed. Whether the patients had an impression of the clinician's own preference for either NIPT or invasive PND was measured by one item ('I feel like the choice I made had the doctor's preference'), answered on a 10-point visual analogue scale. We were especially interested in the distribution of high scores per clinician, indicating that the patient followed a clearly expressed preference of the clinician. Therefore, we reported scores $>8$ on this item per clinician. The measure of informed choice (MIC) was part of the questionnaire and previously designed to assess the level of informed decision-making after pre-test counseling [9]. The MIC consists of two scales; knowledge (with a reliability of $\alpha=$ 0.55 (ref. 9)) and attitude (with a reliability of $\alpha=0.78$ (ref. 9)). Some concerns have been raised about the adequacy of the attitude scale in measuring informed choice when offering a choice between NIPT and invasive PND, since attitude is not a unidimensional trait, but rather multidimensional (van der Steen et al., manuscript in preparation). For the current study, we therefore decided to only report the knowledge scale. The knowledge scale has nine multiple-choice questions regarding the test capacities of NIPT and invasive PND.

\section{Quantitative analysis}

To analyze the data, the multiple-choice answers of the MIC knowledge scale were dichotomized, where ' 0 ' represented an incorrect answer and ' 1 ' a correct answer. Sufficient knowledge was determined to be seven $(7 / 9=77.8 \%)$ or more correct answers on the MIC knowledge scale. We chose such a conservative criterion because we place great priority on thorough and extensive provision of information during counseling. Chi square tests were used to test differences in patients' total knowledge scores between clinicians on the MIC knowledge scale. To evaluate the differences on individual items of the MIC between clinicians, McNemar tests were conducted. Paired samples $t$-tests were used to investigate the differences in total knowledge score of patients between clinicians. Chi square tests were used to test differences in the uptake ratio of NIPT or PND between clinicians and to test for differences in patient characteristics between clinicians. For all statistical tests, a significance level of $\alpha=0.05$ was used.
Table 1 Clinicians and their individual characteristics as derived from the semi-structured interviews

\begin{tabular}{llll}
\hline Clinician & $\begin{array}{l}\text { Information } \\
\text { centeredness } \\
\text { (scale 1-5) }\end{array}$ & $\begin{array}{l}\text { Patient } \\
\text { centeredness } \\
\text { (scale 1-5) }\end{array}$ & $\begin{array}{l}\text { Level of non- } \\
\text { directivity } \\
\text { (scale 1-5) }\end{array}$ \\
\hline 1 & 4.3 & 4.5 & 4.5 \\
2 & 4.5 & 3.8 & 3.0 \\
3 & 4.0 & 4.0 & 2.8 \\
4 & 3.3 & 2.5 & 3.5 \\
5 & 4.0 & 3.8 & 5.0 \\
\hline
\end{tabular}

Clinician characteristics were derived as the mean rating based on scoring of the interviews by 4 separate researchers (SS; DH; SR; AT)

\section{Results}

\section{Clinician characteristics}

The mean scores on the themes of level of informationcenteredness, patient-centeredness, and non-directivity per clinician are displayed in Table 1 . The average percentage of absolute agreement between researchers was $61.7 \%$ (Min $=50 \%, \operatorname{Max}=100 \%)$ and the percentage of ratings with not more than one point difference between researchers was $83.3 \%$ (Min $=75 \%$, Max $=100 \%)$. Clinicians do not differ in their level of information-centeredness, but do differ in their level of patient-centeredness and their level of non-directivity. Figure 2 shows interview findings and quotes to illustrate and support the findings in this paper.

\section{Patients' group differences}

\section{Demographics}

The mean age of patients was 34.6 years. Between patients of different clinicians, there were no significant differences in demographic variables, except for religiosity, and having previous children (as depicted in Table 2); 83\% of patients from clinician 5 did not have previous children, while the other clinicians more often saw patients that did already have children, and $40 \%$ of the patients from clinician 4 were religious, vs. $4 \%$ of the patients from clinician 3. Between clinicians, patient groups did also not differ regarding their anxiety symptoms, which were elevated for all women, and their FTS results (depicted as risk denominators).

\section{Choice ratios}

Patients' choices for either NIPT or PND differed significantly between clinicians $\left(\chi^{2}(4)=11.98, p=0.017\right)$. The largest difference was found between clinician 2 and clinician 5, being 35 vs. $4 \%$ opting for invasive PND, as depicted in Fig. 3. 


\begin{tabular}{|c|c|c|c|}
\hline Clinician & Information-centeredness & Patient-centeredness & Non-directivity \\
\hline 1 & $\begin{array}{l}\text { 'I am talking a lot! You must give } \\
\text { patients a lot of information. I start } \\
\text { with the invasive test. It is a diagnostic } \\
\text { test and NIPT gives a probability of } \\
\text { trisomy } 21,18 \text { and } 13 \text {. I ask them if } \\
\text { they have heard about it. If they say } \\
\text { yes, I do not go into a lot of detail } \\
\text { about it. I ask them if they know } \\
\text { what it is, and what they are going } \\
\text { to do in case of an abnormal result.' }\end{array}$ & $\begin{array}{l}\text { 'I always start with; 'How are you? } \\
\text { Did the abnormal FTS result come as } \\
\text { a shock? How are you feeling about the } \\
\text { result now? Do you already know what } \\
\text { your preference for testing is?' If I } \\
\text { don't do this, then they are not open } \\
\text { to my more technical information } \\
\text { about NIPT/PND.' }\end{array}$ & $\begin{array}{l}\text { 'Non-directive counseling. } \\
\text { Completely neutral. I don't know...I } \\
\text { think I am trying my best to do that. } \\
\text { But I have my own style and the way } \\
\text { you communicate risks is of big } \\
\text { influence on the patients' perception } \\
\text { of that risk. You always bring a piece } \\
\text { of your personality into the counseling. } \\
\text { I try to be as neutral as possible. I take } \\
\text { the patient and her background and } \\
\text { emotions into account.' }\end{array}$ \\
\hline 2 & $\begin{array}{l}\text { 'I explain them there are three options; } \\
\text { no further testing, NIPT or invasive } \\
\text { PND and about the technical } \\
\text { capacities of these tests. We are } \\
\text { looking at all the chromosomes on a } \\
\text { detailed level and it is possible to } \\
\text { detect thousands of other } \\
\text { aberrations that might be equally } \\
\text { relevant, and the background risk is } \\
\text { the same for everyone in the } \\
\text { population.' }\end{array}$ & $\begin{array}{l}\text { 'I always ask: Do you think it is } \\
\text { important to have a definite result? } \\
\text { Do you think it is important to have a } \\
\text { fast result? How much tolerance for } \\
\text { uncertainty do you have? Are you } \\
\text { afraid of risks? What are you going to } \\
\text { do with a normal/abnormal test result? } \\
\text { Have you thought about a termination } \\
\text { of pregnancy? I am emphasizing they } \\
\text { should make a choice that fits their } \\
\text { personal values most.' }\end{array}$ & $\begin{array}{l}\text { 'I tell that with invasive PND, you test } \\
\text { for more than just the common } \\
\text { trisomies. I tell that NIPT is a good } \\
\text { screening test, and invasive PND } \\
\text { provides certainty. The additional } \\
\text { risk of a miscarriage is negligible. I } \\
\text { also talk about the expanded scope of } \\
\text { invasive testing. The extra } \\
\text { information PND yields is a bonus.' } \\
\text { 'I believe in non-directivity, however, } \\
\text { you cannot filter out things like non- } \\
\text { verbal communication or unbalanced } \\
\text { time distribution when explaining } \\
\text { NIPT or invasive PND.' }\end{array}$ \\
\hline 3 & $\begin{array}{l}\text { 'I start with the FTS result. Then I ask } \\
\text { if they know what chromosomes are. I } \\
\text { explain that chromosomes are } \\
\text { genetic building blocks, and } \\
\text { sometimes there is a bit too much or } \\
\text { too little of it. If that's the case, then it } \\
\text { might have consequences for the fetus. } \\
\text { To test the chromosomes, you can opt } \\
\text { for NIPT or PND. I weigh the } \\
\text { patient's specific FTS result to the } \\
\text { risk of a miscarriage due to the } \\
\text { invasive procedure and the chance } \\
\text { to detect something with NIPT.' }\end{array}$ & $\begin{array}{l}\text { 'My story is always more or less the } \\
\text { same, with small variations; I explain } \\
\text { what chromosomes are, how the } \\
\text { invasive PND procedure works, what } \\
\text { the miscarriage risk is, what the pros } \\
\text { and cons of both NIPT and invasive } \\
\text { PND are.' 'I ask about the family } \\
\text { structure and living situation. How } \\
\text { many previous kids? Do those have } \\
\text { special needs? What are your } \\
\text { resources?' 'I also talk about the } \\
\text { personal values of the women or } \\
\text { couple.' }\end{array}$ & $\begin{array}{l}\text { 'I do not give advice, I counsel people. } \\
\text { They should make their own choice. I } \\
\text { do affirm them in their choices, but I } \\
\text { never try to 'talk them into' } \\
\text { anything. Sometimes you need to } \\
\text { decide together with the patient. It is } \\
\text { important that people do not feel regret } \\
\text { for their choices afterwards.' 'I think } \\
\text { we should keep doing invasive tests } \\
\text { and I am pro-invasive testing... oh, I } \\
\text { am not only pro-invasive, I am also } \\
\text { pro-NIPT by the way...' }\end{array}$ \\
\hline 4 & $\begin{array}{l}\text { 'I start with the increased FTS result } \\
\text { and tell them that they can accept } \\
\text { this risk and do nothing or proceed } \\
\text { with NIPT/PND. I tell NIPT is not } \\
\text { that reliable and only for trisomy } 21 \text {, } \\
18 \text { and } 13 \text {. About invasive PND I tell } \\
\text { that we 'just look at all the other } \\
\text { chromosomes' as well. I do not go } \\
\text { into detail about this. I also tell them } \\
\text { that there is a very small risk of a } \\
\text { miscarriage.' }\end{array}$ & $\begin{array}{l}\text { 'It is not my job to explore which } \\
\text { choice would be the best fit for the } \\
\text { patient, is it? It is up to the couple to } \\
\text { decide which road they could best } \\
\text { take.' }\end{array}$ & $\begin{array}{l}\text { 'I think non-directivity is a great } \\
\text { principle, but that it is hard to } \\
\text { maintain all the time. But yes, I do } \\
\text { think it is very desirable to counsel in a } \\
\text { non-directive fashion. I try to counsel } \\
\text { as non-directive as possible and to give } \\
\text { the information about it as clearly as I } \\
\text { can. When they ask me for advice, I } \\
\text { say that it is not my child and I am not } \\
\text { the one who is pregnant, but I am } \\
\text { willing to go through all information } \\
\text { about the options again. I tell them } \\
\text { the risk of a miscarriage is actually } \\
\text { quite small, but when it happens, it } \\
\text { is a great tragedy.' }\end{array}$ \\
\hline 5 & $\begin{array}{l}\text { 'I tell them that NIPT, like FTS, is } \\
\text { also a probabilistic test, no } 100 \% \\
\text { certainty. Invasive PND does give } \\
\text { certainty and is capable to detect } \\
\text { more aberrations. I tell them that } \\
\text { NIPT has no miscarriage risk and is } \\
\text { designed to detected trisomy } 21,18 \\
\text { and } 13 \text {. I also explain the symptoms } \\
\text { of these trisomies and what it might } \\
\text { mean for the fetus.' }\end{array}$ & $\begin{array}{l}\text { 'I open my counseling with informing } \\
\text { about how the woman is doing when } \\
\text { she enters my room. I ask, 'How are } \\
\text { you? How do you feel about the } \\
\text { abnormal FTS result? What are you } \\
\text { going to do with the outcomes of a } \\
\text { follow-up test (in the case of } \\
\text { NIPT/PND)? I try to ask them about } \\
\text { the way they feel about their choice, } \\
\text { whether it be NIPT, PND or no } \\
\text { further testing.' }\end{array}$ & $\begin{array}{l}\text { 'I think it is most important to } \\
\text { explain people what both options } \\
\text { comprise and what the consequences } \\
\text { can be. I never ever give advice. I tell } \\
\text { them that they have to make their own } \\
\text { choices, even if they ask me what I } \\
\text { would do.' 'I do say that in the } \\
\text { experience of my patients, chorionic } \\
\text { villus sampling is often perceived as a } \\
\text { more unpleasant procedure.' }\end{array}$ \\
\hline
\end{tabular}

Fig. 2 Quotes to illustrate clinicians' answers and individual characteristics 
Table 2 Demographic data of participating women $(N=181)$

\begin{tabular}{|c|c|c|c|c|c|c|c|c|c|}
\hline & Total & \multicolumn{2}{|c|}{ Percentage } & C 1 & $\mathrm{C} 2$ & $\mathrm{C} 3$ & $\mathrm{C} 4$ & $\mathrm{C} 5$ & $p$ value $(\chi)$ \\
\hline \multicolumn{2}{|l|}{ Educational level } & & & & & & & & 0.106 \\
\hline Low/intermediate & 59 & $33 \%$ & & $41 \%$ & $28 \%$ & $17 \%$ & $27 \%$ & $48 \%$ & \\
\hline High & 122 & $67 \%$ & & $59 \%$ & $72 \%$ & $83 \%$ & $73 \%$ & $52 \%$ & \\
\hline \multicolumn{2}{|l|}{ Nationality } & & & & & & & & 0.293 \\
\hline Dutch & 167 & $92 \%$ & & $94 \%$ & $89 \%$ & $96 \%$ & $87 \%$ & $100 \%$ & \\
\hline Other & 14 & $8 \%$ & & $6 \%$ & $11 \%$ & $4 \%$ & $13 \%$ & $0 \%$ & \\
\hline \multicolumn{2}{|l|}{ Religiosity } & & & & & & & & $0.007^{*}$ \\
\hline Religious & 38 & $21 \%$ & & $10 \%$ & $24 \%$ & $4 \%$ & $40 \%$ & $35 \%$ & \\
\hline Non-religious & 143 & $79 \%$ & & $90 \%$ & $76 \%$ & $96 \%$ & $60 \%$ & $65 \%$ & \\
\hline \multicolumn{2}{|l|}{ Previous children } & & & & & & & & $0.001^{*}$ \\
\hline Yes & 101 & $56 \%$ & & $71 \%$ & $57 \%$ & $57 \%$ & $67 \%$ & $17 \%$ & \\
\hline No & 80 & $44 \%$ & & $29 \%$ & $43 \%$ & $43 \%$ & $33 \%$ & $83 \%$ & \\
\hline \multicolumn{2}{|l|}{ Previous miscarriages } & & & & & & & & 0.793 \\
\hline Yes & 46 & $25 \%$ & & $32 \%$ & $35 \%$ & $43 \%$ & $50 \%$ & $31 \%$ & \\
\hline No & 82 & $45 \%$ & & $68 \%$ & $65 \%$ & $57 \%$ & $50 \%$ & $69 \%$ & \\
\hline \multirow[t]{2}{*}{ Missing } & 53 & $29 \%$ & & & & & & & \\
\hline & Mean & SD & $\mathrm{C} 1$ & $\mathrm{C} 2$ & & $\mathrm{C} 3$ & $\mathrm{C} 4$ & $\mathrm{C} 5$ & $p$ value $(\chi)$ \\
\hline Anxiety (STAI) & 45.1 & 12.9 & 47.6 & 44.4 & & 42.8 & 42.4 & 46.4 & 0.466 \\
\hline FTS result & 91.1 & 55.3 & 78.8 & 104.4 & & 88.4 & 60.4 & 91.6 & 0.162 \\
\hline
\end{tabular}

*Significant $(<0.05)$

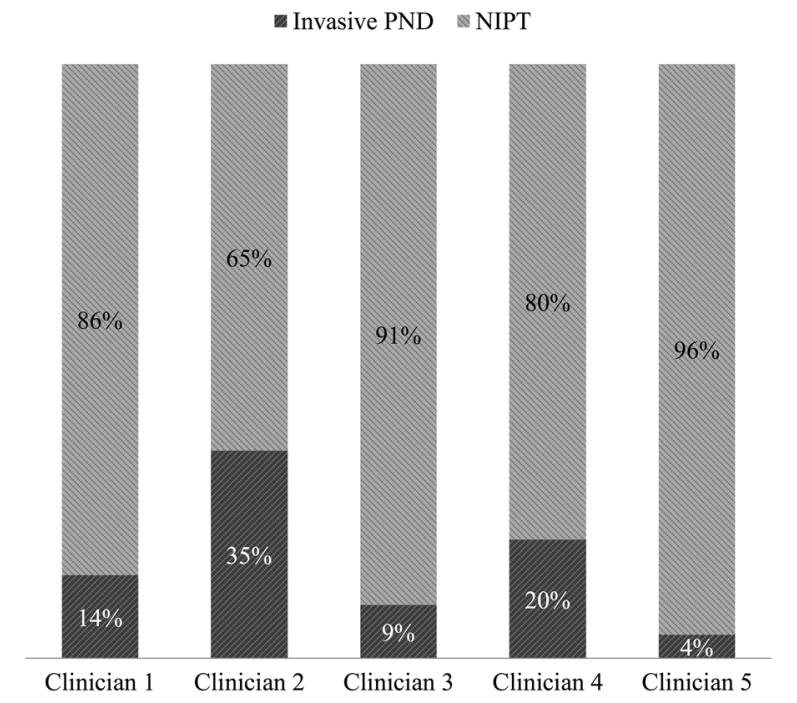

Fig. 3 Ratio of patients' choices for NIPT or invasive PND between clinicians $(N=181)$

\section{Patients' impression of clinician preference}

The mean and median scores of the question 'I feel like the choice I made had the doctor's preference' are displayed between clinicians in Table 3. Table 3 also depicts the percentage of patients for each clinician who indicated they had
Table 3 Mean and median item scores between clinicians and percentage of patients $(N=181)$ who indicated they had an impression $(\geq 8$, range $0-10)$ of the clinician's preference and chose in accordance

\begin{tabular}{llllll}
\hline & $N$ & Mean & Median & $\begin{array}{l}\text { Frequency } \\
\text { score } \geq 8\end{array}$ & $\begin{array}{l}\text { Percent } \\
\text { score } \geq 8\end{array}$ \\
\hline Clinician 1 & 49 & 3.68 & 4.50 & 6 & $12.0 \%$ \\
Clinician 2 & 71 & 4.04 & 4.00 & 16 & $21.6 \%$ \\
Clinician 3 & 23 & 3.00 & 2.00 & 3 & $13.0 \%$ \\
Clinician 4 & 15 & 4.00 & 5.00 & 2 & $13.3 \%$ \\
Clinician 5 & 23 & 2.65 & 1.00 & 2 & $8.7 \%$ \\
\hline
\end{tabular}

an impression of their clinician's preference. Between 9 and $22 \%$ of the patients had an indication of the clinician's preference and chose in accord with perceived clinician preference.

\section{Patients' knowledge scores}

Patients' mean knowledge scores were high. Most pregnant women and their partners answered all questions correct and displayed good testing knowledge. Knowledge scores did not differ across clinicians. However, patients' individual item scores of either NIPT or PND questions differed significantly across clinicians, as depicted in Table 4. 
Table 4 Mean MIC Knowledge scores between clinicians. Significant differences on NIPT or invasive PND questions answered correct were observed between clinicians and marked with *

\begin{tabular}{|c|c|c|c|c|c|c|}
\hline Item & $\begin{array}{l}\text { Total } N= \\
181\end{array}$ & $\begin{array}{l}\mathrm{C} 1 N= \\
49\end{array}$ & $\begin{array}{l}\mathrm{C} 2 \\
N=71\end{array}$ & $\begin{array}{l}\mathrm{C} 3 \\
N=23\end{array}$ & $\begin{array}{l}\mathrm{C} 4 \\
N=15\end{array}$ & $\begin{array}{l}\mathrm{C} 5 \\
N=23\end{array}$ \\
\hline 1. Which material is used for NIPT testing? & 0.99 & 1.00 & 1.00 & 1.00 & 1.00 & 1.00 \\
\hline 2. Which aberrations does the NIPT detect? & 0.99 & 1.00 & 0.96 & 1.00 & 1.00 & 1.00 \\
\hline 3. What is done to verify an abnormal NIPT result? & 0.96 & 1.00 & 0.94 & 1.00 & $0.80 *$ & 0.93 \\
\hline 4. What is the miscarriage risk of the NIPT? & 0.98 & 1.00 & 0.98 & 1.00 & 0.90 & 1.00 \\
\hline 5. After how many weeks of gestation can NIPT be performed? & 0.95 & 0.95 & 0.96 & 1.00 & 0.90 & 0.86 \\
\hline 6. What is the reliability of the NIPT? & 0.85 & 0.95 & $0.64 *$ & 0.69 & 0.80 & 0.93 \\
\hline $\begin{array}{l}\text { 7. Which conditions or abnormalities can be detected with invasive } \\
\text { PND? }\end{array}$ & 0.58 & 0.65 & 0.68 & 0.69 & 0.80 & $0.50 *$ \\
\hline $\begin{array}{l}\text { 8. What is a possible advantage of invasive prenatal testing for a } \\
\text { pregnant woman and her partner? }\end{array}$ & 0.88 & 0.89 & 0.88 & 1.00 & 1.00 & 0.79 \\
\hline $\begin{array}{l}\text { 9. What is a possible advantage of NIPT for a pregnant woman and } \\
\text { her partner? }\end{array}$ & 0.80 & 0.84 & 0.82 & 0.85 & 0.80 & 0.93 \\
\hline Total knowledge score & 7.97 & 8.27 & 7.86 & 8.23 & 8.00 & 7.93 \\
\hline
\end{tabular}

Note: For each item $0=$ incorrect and $1=$ correct. The range of the total score is 0 to 9 . $*$ Significant difference

$C$ clinician

\section{Discussion}

Prenatal genetic counseling has become increasingly demanding due to the more complex information resulting from technological progress. Consequently, for pregnant women and their partners, the decision-making process may be under more pressure than ever before. Such pressure requires thorough, high quality counseling. Assuming all clinicians commit to the recommendations made by the Dutch Health Council [17] in their counseling, overall uptake ratios and the clinicians' views on the content and approach of their counseling should be approximately equal in the grand total. All clinicians in our study provide and discuss the relevant information that is necessary to meet the first requirement of informed decision-making, which was validated by the high knowledge scores of pregnant women. However, in this study we found differences between clinicians in their patient-centeredness, level of non-directivity, and the test uptake of patients.

Regarding patient-centeredness, some clinicians stated that they actively explore the patient's values and attitudes, whereas others were less inclined to address the patient's feelings and cognitions about the test options of NIPT and invasive PND (as illustrated by the quotes). The patientclinician relationship (e.g., affective communication, collaboration, goal consensus, positive regard) accounts for a substantial part of the psychological outcomes in a prenatal care trajectory $[2,18-20]$. We therefore consider this theme to be of great importance. Providing space for patients to share their considerations and thoughts leads to a greater level of perceived patient-centeredness [2]. It is important for clinicians to provide guidance by eliciting information from their patients about their needs and by asking questions about their values and attitudes. Individual differences require clinicians to adjust, i.e., personalize, their counseling.

Regarding how clinicians valued non-directivity, we observed differences between clinicians, as indicated by their quotes. Although the concept of (non)directivity has been used for more than four decades, there is still no consensus about the definition of directiveness and nondirectiveness. Kessler [5, 7] has argued that not being directive is not the same as being non-directive. He states that being directive involves a degree of persuasive coercion. However, the absence of persuasive coercion does not imply non-directivity. Non-directiveness is an active strategy that requires counseling skills that aim to support the patient's autonomy and self-directedness and provides them with a way of thinking about their considerations. According to Evans [21], a misunderstanding of the concept of nondirectivity may lead the clinician to adopt a stance of passivity or defensive avoidance rather than engaged neutrality.

Moreover, clinicians might be unaware of their directiveness [5]. In our study, clinicians' quotes show that a framing effect may implicitly be present in their counseling, for example when they spend more time discussing one test than discussing the other. Differences in risk communication also become apparent from the interview quotes. Some clinicians frame their information by using words such as "negligible", "only $1 / 1000 "$, and "extremely small" when communicating the miscarriage risk. Other clinicians make it much more personal by stating that 'the risk is small, but when it happens, it is a great tragedy'.

Furthermore, all clinicians are about the same age (42-51 years) and have been active in their profession for a long time. 
For them, invasive testing has been the standard of prenatal genetic testing for years. This may lead some of them to describe invasive PND as such, while the testing options of either NIPT or PND are essentially different, since they have been designed for different purposes; invasive PND is a diagnostic test, while NIPT is a screening test. Clinicians also indicated that a substantial number of patients already have a strong preference for NIPT when they enter the counseling. As the clinicians reported, the information that is provided to them by primary or secondary care is often framed, shaped, or even incorrect in favor of NIPT. A skewed level of prior knowledge may motivate some clinicians to elaborate more on both test options and to balance the knowledge of their patients. However, other clinicians may become demotivated, as they feel like they are repeatedly making up for other referrers' misconceptions. These matters of word choice and non-verbal communication may unintentionally steer the decision-making process of patients, which is hard to prevent. However, this framing effect may be counterbalanced by skillful counseling.

As a final remark, there are important individual and cultural differences among patients that may complicate the adoption of a non-directive attitude [22]. When facing such a clinical, statistical, and emotional complex decision, it may be that while some patients are self-directive and prefer to optimize their choice-relevant knowledge to make the most informed decision possible, others feel overwhelmed and are more inclined to rely on the clinicians expertise, consciously or unconsciously handing over the responsibility for their decision. Corresponding to these individual differences, patients may need different levels of (non-) directiveness from their clinician [23].

Clinicians in our study differed in the percentage of their patients opting for invasive PND and NIPT. Moreover, there was a group of patients who had an impression of their clinician's preference for either test. The unique offer of high resolution microarray may incline the clinicians to guide their patients towards opting for invasive PND. The finding that nearly $20 \%$ of pregnant women opted for invasive PND in Erasmus Medical Center, compared to about 3\% nationwide, may indicate such a tendency. However, there are also contradictory data suggesting that the difference in uptake cannot be explained by the unique offer. These data were retrieved from non-academic centers in the region that offered the same high resolution SNP array to their patients by sending their genetic material to the Erasmus Medical Center's lab for chromosomal examination at submicroscopic level [9]. Remarkably, none of these pregnant women who were offered the same options as in Erasmus Medical Center chose invasive PND [9]. Whether the impression of the clinician's preference had influenced the pregnant woman's eventual decision needs to be further investigated. It may well be that the patient has made an informed choice and has the same preference for testing as the clinician. Furthermore, the perceived preference of the clinician may rather be an indication of shared decision-making and personalized counseling, than of undesired influence and directivity [24].

This study gave a first exploration of how clinicians' differing approaches affect patients' choice. We combined both qualitative data from the interviews with clinicians and quantitative data of patients. Although we found differences in patient-centeredness and non-directivity between clinicians, we were unable to link these differences to differences in patients' test uptake. It is possible that some of the differences in patient decisions may simply reflect differences in sample sizes. Clinician 2 saw more patients than clinicians 3, 4, and 5 combined. Demographic data showed that clinician 5 counseled the most patients with no previous children and also had the highest proportion of people opting for NIPT. This finding may reflect this group's reluctance to put a first pregnancy at risk of miscarriage. Another explanation for why we were unable to link clinician differences to patients' test uptake, may be that the differences in clinician characteristics are too subtle to identify a clear pattern related to patients' choice based on a limited number of clinicians. Also, clinicians' answers may have been subjected to what they thought was socially desirable. Another limitation of this study is the subjective scoring of clinician characteristics by the researchers. Since some of the researchers (SS; SR) know the clinicians and are on good terms with each other, they may have rated them more positively. However, scorings were not exclusively positive and varied considerably between researchers. Most importantly, without creating this safe environment for the counselors, they maybe would have been reluctant to participate and their answers would have been even more socially desirable.

We suggest that further research finds a way to study the actual counseling provided by means of analyzing recorded counseling sessions in a larger, more powerful research design, to gain more insight into clinicians' approach and content. Also, given the higher invasive PND uptake rate in the Erasmus Medical Center compared to other academic centers, it would be interesting to compare clinician approach and counseling content between different academic centers and/or hospitals.

\section{Implications}

Clinicians differed in their prenatal genetic counseling approach and content. Our results indicate that the information provision during counseling is sufficient. Patientcenteredness differs between clinicians and may be improved by putting more emphasis on exploring patients' meaning and personal significance during the counseling. We advocate that this theme should be elicited in training modules 
for clinicians. Another important theme to emphasize during training modules is the paradigm of non-directivity. The understanding of this concept should shift from emphasizing what clinicians should not do, i.e., persuasive coercion and giving advice, possibly inducing passivity, to what they should do, i.e., promoting patient's autonomy and selfdirectedness by aiming for patients to feel understood, in control, and competent. The latter involves an active attitude and requires more counseling skills.

\section{Conclusion}

To conclude, patients' choice ratio for either NIPT or invasive PND differed significantly between clinicians. In our study, clinicians seem to influence the choices their patients make by means of their counseling approach and content. It is important that clinicians reflect on their potential impact on the patients' decision-making process. A framing effect may unintentionally steer the decision-making process of patients, which is hard to prevent. The challenge remains to affect the decision-making process in the most positive and skillful manner; to facilitate well-deliberated and informed choices, to determine the counseling needs of pregnant women and their partners, and to promote autonomy and self-directedness.

Acknowledgements We thank the clinicians for participating in the interviews.

\section{Compliance with ethical standards}

Conflict of interest The authors declare that they have no conflict of interest.

\section{References}

1. Michie S, Dormandy E, Marteau TM. The multi-dimensional measure of informed choice: a validation study. Patient Educ Couns. 2002;48:87-91.

2. Veach PM, Bartels DM, Leroy BS. Coming full circle: a reciprocal-engagement model of genetic counseling practice. $\mathrm{J}$ Genet Couns. 2007;16:713-28.

3. Dahl K, Hvidman L, Jorgensen FS, Kesmodel US. Knowledge of prenatal screening and psychological management of test decisions. Ultrasound Obstet Gynecol. 2011;38:152-7.

4. Kleinveld JH, Ten Kate LP, van den Berg M, van Vugt JM, Timmermans DR. Does informed decision making influence psychological outcomes after receiving a positive screening outcome? Prenat Diagn. 2009;29:271-3.

5. Kessler S. Psychological aspects of genetic counseling. XI. Nondirectiveness revisited. Am J Med Genet. 1997;72:164-71.

6. Farrelly E, Cho MK, Erby L, Roter D, Stenzel A, Ormond K. Genetic counseling for prenatal testing: where is the discussion about disability? J Genet Couns. 2012;21:814-24.

7. Kessler S. Psychological aspects of genetic counseling: VII. Thoughts on directiveness. J Genet Couns. 1992;1:9-17.
8. Oepkes D, Page-Christiaens GC, Bax CJ, Bekker MN, Bilardo CM, Boon EM, et al. Trial by Dutch laboratories for evaluation of non-invasive prenatal testing. Part I-clinical impact. Prenat Diagn. 2016;36:1083-90.

9. van der Steen SL, Bunnik EM, Polak MG, Diderich KE, Verhagen-Visser J, Govaerts LC, et al. Choosing between higher and lower resolution microarrays: do pregnant women have sufficient knowledge to make informed choices consistent with their attitude? J Genet Couns. 2018;27:85-94.

10. Srebniak MI, Mout L, Van Opstal D, Galjaard RJ. 0.5 Mb array as a first-line prenatal cytogenetic test in cases without ultrasound abnormalities and its implementation in clinical practice. Hum Mutat. 2013;34:1298-303.

11. Sachs A, Blanchard L, Buchanan A, Norwitz E, Bianchi DW. Recommended pre-test counseling points for noninvasive prenatal testing using cell-free DNA: a 2015 perspective. Prenat Diagn. 2015;35:968-71.

12. de Jong A, Dondorp WJ, de Wert GM. The scope of prenatal diagnostic testing for chromosomal aberrations: broad or narrow? Ethical considerations on the choice of tests. Ned Tijdschr Geneeskd. 2009;153:A1060.

13. de Jong A, Dondorp WJ, Krumeich A, Boonekamp J, van Lith JM, de Wert GM. The scope of prenatal diagnosis for women at increased risk for aneuploidies: views and preferences of professionals and potential users. J Community Genet. 2013;4:125-35.

14. Riedijk S, Diderich KE, van der Steen SL, Govaerts LC, Joosten M, Knapen MF, et al. The psychological challenges of replacing conventional karyotyping with genomic SNP array analysis in prenatal testing. J Clin Med. 2014;3:713-23.

15. Benkendorf JL, Prince MB, Rose MA, De Fina A, Hamilton HE. Does indirect speech promote nondirective genetic counseling? Results of a sociolinguistic investigation. Am J Med Genet. 2001;106:199-207.

16. Spielberger CD. State-Trait Anxiety Inventory: Bibliography. 2nd edn. Palo Alto, CA 1983.

17. The Dutch Health Council. NIPT: dynamics and ethics of prenatal screening. The Hague: Health Council of the Netherlands, 2013; publication no. 2013/34: 21-28. https://www.gezondheidsraad.nl/ en/task-and-procedure/areas-of-activity/prevention/nipt-dyna mics-and-ethics-of-prenatal-screening isbn $=978-90-5549-983-0$

18. Bernhardt BA, Biesecker BB, Mastromarino CL. Goals, benefits, and outcomes of genetic counseling: client and genetic counselor assessment. Am J Med Genet. 2000;94:189-97.

19. Elwyn G, Gray J, Clarke A. Shared decision making and nondirectiveness in genetic counselling. J Med Genet. 2000;37:135-8.

20. Sep MS, van Osch M, van Vliet LM, Smets EM, Bensing JM. The power of clinicians' affective communication: how reassurance about non-abandonment can reduce patients' physiological arousal and increase information recall in bad news consultations. Exp Study Using Analog Patients Patient Educ Couns. 2014;95:45-52.

21. Evans C. Genetic Counselling: A Psychological Approach. New York, USA: Cambridge University Press; 2006.

22. Raza E, Atar M. Nondirectiveness and its lay interpretations: the effect of counseling style, ethnicity and culture on attitudes towards genetic counseling among Jewish and Bedouin respondents in Israel. J Genet Couns. 2003;12:313-32.

23. Armstrong K, Stopfer J, Calzone K, Fitzgerald G, Coyne J, Weber B. What does my doctor think? Preferences for knowing the doctor's opinion among women considering clinical testing for BRCA1/2 mutations. Genet Test. 2002;6:115-8.

24. van den Berg M, Timmermans DR, Kleinveld JH, van Eijk JT, Knol DL, van der Wal G, et al. Are counsellors' attitudes influencing pregnant women's attitudes and decisions on prenatal screening? Prenat Diagn. 2007;27:518-24. 